\title{
DR. J.D. DU TOIT EN DIE ONDERWYS
}

J.D. du Toit, 'n seun van die grondlegger, eintlik die vader van Christelik-nasionale onderwys in Suid-Afrika, het sy hele opvoeding ontvang aan skoolinrigtings met 'n Christelik-nasionale gees en rigting.

Sy cerste skool was 'n C.N.O.-skool en die laaste inrigting waaraan hy gestudeer het, was 'n C.N.-Universiteit. As leerling en as student het hy nooit 'n voet in 'n staatskool of staatsinrigting vir hoër onderwys gesit nie. Daarvoor het sy oortuigde vader gesorg.

Dit sal ons dan ook nie verbaas dat J.D. du Toit hom lewenslank in sy amptelike hoedanigheid beywer het vir C.N.O. nie. Hy het hom gegee aan die stigting, instandhouding en beheer van C.N.O. skole: hy het die beginsel van C.N.O. in woord en in geskrif gestel, ontwik kel en verdedig.

Sy vader, wat predikant van die Nederduits Gereformeerde Kerk in De Paarl was, het deur sy geskrifte, veral De Christelijke School in hare verhouding tot Kerk en Staat 1876, en deur sy aandeel aan die stigting van De Gedenkschool op Daljosafat hom betuig as die vooraanstaande pleitbesorger van C.N.O. Op grond van sy werk in De Paarl het die Transvaalse Owerheid hom in 1882 as Superintendent van Opvoeding benoem. In die Transvaal het ds. Du Toit 'n stelsel van C.N.O.-skole in die lewe geroep en in stand gehou.

Toe ds. Du Toit in 1884 op 'n amptelike sending na Europa moes gaan, het hy sy seun Japie na De Paarl geneem om aan die Gedenkschool sy eerste beginsels van kennis en kundigheid op te doen. Na sy terugkeer uit Europa het ds. Du Toit vir sy kinders 'n gocwernante as onderwyseres benoem. In 1888 het hy sy seun na 'n Duitsc Sendingskool op Pretoria gestuur. In 1889 het ds. Du Toit weer na Europa vertrek en is Japie vir die jare 1890 tot 
1894 weer na die Gedenkschool. In 1895 lê die jong seun deur private studie sy Matrikulasic-eksamen af. Daarna het sy vader hom na Burgersdorp gestuur om aan die Teologiese Skool van die Gereformeerde Kerk vir predikant te studeer. Daar bly hy van 1896 tot 1899 . Kort na die uitbreck van die Tweede Vryheidsoorlog is hy na Nederland om aan De Vrije Universiteit, Amsterdam, in die Teologie verder te studeer en om in 1903 sy doktorsgraad met 'n dissertasie oor Het Methodisme te verwerf.

Hy keer dan na Suid-Afrika terug en word op 25 September 1903 bevestig as predikant van die Gereformeerde Kerk op Potchefstroom. Hier het hy feitlik lewenslank gewoon.

Ds. Du Toit het hom in sy nuwe werkkring onmiddellik geskaar aan die kant van die gelowige Afrikaner in die Transvaal, wat 'n eie C.N.O.-skoolstelsel gestig en in stand gehou het. Op die eerste Kerkraadsvergadering, 31 Oktober 1903, het die jong predikant sy kerkraad ernstig toegespreek insake die onderwys en die ouderlinge het daarop onderneem om die ouers by huisbesoek behoorlik tc ondervra en in te lig. Op 2 April 1904 het die kerkraad besluit om sy „Ou Kerkie" beskikbaar te stel aan 'n private, vrye, Christelike skool. In die dorp en distrik is 'n hele aantal C.N.O.skole aan die gang gehou, waaroor daar in die Kerklike Almanak volledig gerapporteer word. Op vergadering na vergadering het ds. Du Toit die saak van C.N.O. gestel; hy het dringender geword hoe dreigender die oorname van alle C.N.O.skole deur die Transvaalse Owerheid.

Toe die C.N.O.beweging in 1907 doodgeloop het, deurdat al die skole onder die Regering se vlerke ingegaan het, het ds. Du Toit bly voortwerk vir die stigting van vrye Christelike skole en die herlewing van die C.N.O.-beweging. Hy het dan ook al sy kragte ingegooi by die stigting van so 'n skool verbind aan dic Teologiese Skool, die sogenaamde Voorbereidende School. Hy was een van die stigterslede en cen van dic Bestuurslede van die skool. Aan die skool het hy self elke Woensdag dogmaticse onderrig gegee. 
In 1908 publiseer dr. Du Toit 'n uiters belangrike kritiek op die godsdiensklousule van die Transvaalse Onderwyswet in sy Christelijke Onderwijs met of zonder Dogma. By die formulering van Du Toit se opvoedkundige gedagtes kom ek weer op die brosjure terug.

„C.N.O. is dood. Lank leef C.N.O." - dit was die grondgedagte van ' $n$ vergadering gehou op Potchefstroom op 6 Julie 1907, bygewoon deur ' $n$ dertigtal bittereinders in die stryd om vrye C.N.O. Onder die bittereinders staan die naam van dr. Du Toit duidelik geskryf. Dit was die begin van openbare kongresse en konferensies oor C.N.O. Die Christelike gemeenskap het die stryd aangebind, en Du Toit word een van die leidende persoonlikhede. Op die samekoms van Julie 1907 het Du Toit, ondersteun deur A.J. van der Walt, voorgestel dat 'n vereniging gestig word oor die hele Suid-Afrika om die beginsel van die Vrye Skool met Staatsubsidie te bevorder en dat 'n kommissie van vyf lede benoem word om 'n program van beginsels en konsep-statute op te stel. Dr. Du Toit het op die kommissie gedien en was die adres vir die te stigte vereniging. Reeds teen September is sodanige vereniginge gestig op Potchefstroom, Gatsrand en enkele ander plekke. In Junic 1908 het Du Toit sy bogenoemde lesing voor die „Vereeniging van Christelijike Belangen” op Pretoria gehou.

Dic cerste groot kongres oor C.N.O. is in Julie 1909 op Pretoria gehou. Daar is dr. Du Toit gekies as lid van die Hoofbestuur. Die tweede kongres is gehou op Steynsburg in Julie 1911. Opnuut is die organisasie lewe ingeblaas: nuwe Statute van 'n Vereniging vir Christelike Skoolonderwys is opgestel en 'n nuwe interprovinsiale Hoofbestuur is gekies waarop dr. Du Toit een van die Transvaalse lede was. Die derde kongres is in Julie 1912 op Potchefstroom gehou en in Oktober 1913 die vierde kongres, en wcl op Bethulie. Dr. Du Toit het nog steeds 'n leidende aandeel behou.

Met dic vicr kongresse is by die owerheid geen vordering gemaak nie. Op 15 September 1915 kan Het Kerkblad nog getuig: 
„C.N.O. nog nic dood nic", al was die toestande baic duister met die opheffing van die Voorbereidende Skool as 'n vrye Christelike skool. Gedurende 1916 vlam die idee van C.N.O. weer vinnig op. In dic begin van 1916 is 'n verdere kongres in Bloemfontein gehou, waar prof. J. Kamp 'n duidelike geluid laat hoor het oor dic beginsel van Grocpskole. Aan hierdie beskouinge van prof. Kamp is deur dr. Du Toit vaste rigting en vorm gegee toe hy in Julie 1917 op dic groot C.N.O.-kongres op Bloemfontein gespreek het oor Die plek van die skool in die samelewing.

Op nog twee kongresse oor C.N.O. sou dr. Du Toit 'n akticwe, leidende figuur wees. Die eerste was 'n konferensie op Potchefstroom gehou op 9 September 1934 waar dr. Du Toit 'n referaat gelewer het oor Die Geskiedenis van die C.N.O. Die tweede was die groot en beslissende C.N.O.-kongres gehou in Julie 1939 op Bloemfontein. Hier het dr. Du Toit 'n voordrag gelewer oor C.N.O. en Godsdiensonderwys. Uit die kongres is gebore die Instituut vir Christelik-nasionale Onderwys wat in 1948 sy bekendgeworde brosjure Die C.N.O.-beleid die lig laat sien het. In die Beleid word dic gedagte van dr. Du Toit grotendeels verwesenlik.

Dr. Du Toit het ook 'n beslissende rol gespeel in die aktiwiteit van die Gereformeerde Kerk as sodanig ten opsigte van C.N.O. In die verband moet verwys word na twee kringe van optrede: die Sinodale Vergaderinge en die redaksic van Die Kerkblad.

Reeds op die eerste Algemene Vergadering van die Transvaal, wat hy as predikant kon bywoon (naamlik in Januarie 1904) is hy aangewys as een van die lede van die Kommissie van C.N.O. Op sy eerste Algemene Sinodale Vergadering (April 1904) op Middelburg, K.P. gehou, het hy aandagtig geluister na 'n grondige bespreking en 'n belangrike besluit oor C.N.O. Op die Transvaalse Algemene Vergadering van Januarie 1909 het dr. Du Toit 'n ernstige pleidooi gelewer oor die onderwyssaak na aanleiding van die Smutswet van 1907. Op sy voorstel is 'n kommissic van twaalf lede (hy was een) benoem „die trouw be- 
loven te strijden voor de zaak van vrije scholen met Staatsubsidie". Hierdie kommissie het saamgewerk in verband met die C.N.O.-kongres van 1909 en in Januarie 1910 aan sy opdraggewer verslag gedoen. Nog ernstiger is die saak bespreek op die Algemene Vergadering in Januarie $1912 \mathrm{en}$ is besluit om 'n protes by die Administrateur in te dien. Die inhoud van die protes vorm 'n belangrike beredenering van die grondbeginsel van C.N.O. Die hele Vergadering het op 23 Januarie sonder vrug sy opwagting gemaak by adm. Johan Rissik. Die idee van die vrye Christelike skool, veral as "Groepskool" is kragtig bevorder in 1918 deurdat die drie Afrikaanse Kerke 'n groot kongres in Pretoria gereël het. Op die kongres in April gehou, het dr. Du Toit 'n kragtige woord gespreek oor De Vrije School. Die kongres het besluit om getuienis namens die Kerke af te lê voor die destydse Kommissie van Ondersoek oor die Transvaalse Onderwys (voorsitter H.L. Malherbe). 'n Spesiale Kommissie van Getuienis is benoem, waarop dr. Du Toit as Gereformeerde verteenwoordiger sitting geneem het. Die getuienis word in die Malherbe-verslag (1920, Art. 125) kort saamgevat onder 7 punte waarin die stem van dr. Du Toit duidelik hoorbaar is (Vgl. ook Het Kerkblad, 15 Mei 1918). Tussen die jare 1920 en 1933 is daar meer in stilte aan die propagering van C.N.O. gewerk. Die Algemene Sinodale Vergadering van die Gereformeerde Kerk het hom in Maart 1933 met sy sitting op Pretoria weer sterk uitgespreek oor die noodsaaklikheid van die vrye Christelike skool, veral as Vrye Groepskool, en grotendeels as uitvloeisel daarvan is die C.N.O.-kongres in September 1934 gehou, waar besluite in die gees van die tussenkerklike kongres van 1918 geneem is. Die laaste openbare deelname van dr. Du Toit in verband met kerklike aksie op die gebied van die C.N.O. het gekom toe die Transvaalse Provinsiale Owerheid weer eens 'n Kommissie van Ondersoek oor die Onderwys (voorsitter ds. Wm. Nicol) in 1936 benoem het. Die Provinsialc Sinode van die Gereformeerde Kerk in Transvaal het in Januarie 1937 'n Onderwyskommissie benoem om getuienis af te lê namens die Gereformeerde Kerk voor die Nicolkommissie. Op die Kommissie het dr. Du Toit weer gedien. Op 29 Maart 1937 is 'n „Bcleidsverklaring" opgestel en op $17 \mathrm{Mei}$ is dit gestel voor 
die Nicolkommissic. Hierdie Beleidsverklaring gee 'n afronding ook aan dr. Du Toit se beskouings oor dic onderwys.

Dr. Du Toit se groot rol in die onderwys blyk finalitêr duidelik uit die baie artikels in Ilet Kerkblad, wadarvan hy redaksielid vir baie jare was. 'n Versameling van die artikels vind die leser in een van die boekdele wat nou tot sy gedagtenis uitgegee is.

Ten slotte mag ook nie verswyg word sy groot betekenis vir die skoolonderwys wat die noodwendige gevolg was van sy reuseaandeel aan die vertaling van die Bybel in Afrikaans en van sy persoonlike berymings van Die Psalms en ander Skrifgedecltes. Die Afrikaanse Bybel was die finale en beslissende bydrac tot die volle ontplooiing van die Afrikaanse Skool in Suid-Afrika. Sonder 'n Afrikaanse Bybel en 'n bundel Afrikaanse gewyde liedere en Psalms is 'n Afrikaanse skool ondenkbaar.

Dr. Du Toit het op die ontwikkeling van dic Christelik hoër onderwys 'n nog duideliker spoor afgedruk as op die van die gewone C.N.O.

Sy optrede hier het reeds vroeg na sy bevestiging as predikant op Potchefstroom begin. Op sy inisiatief het die Potchefstroomsc Kerkraad en gemeente dadelik besluit om geld in te samel met die oog op die verplasing van die Teologiese Skool van Burgersdorp na Potchefstroom. So vind ons reeds dat op 26 Desember 1903 op 'n gemeentevergadering besluit is om lyste in die wyke te laat teken en om, indien nodig, dic gebou op die kerkgronde te laat oprig. Op 13 Februarie 1904 het die kerkraad besluit om ook die plaaslike Skoolraad te nader vir grond vir die Teologiese Skool. Op voorstel van ds. D. Postma en dr. Du Toit het die Algemene Sinodale Kerkvergadering in April 1904 besluit om die Teologiese Skool na Potchefstroom te verplaas. Dr. Du Toit was ook lid van die plaaslike boukommissie van die Teologiese Skool. Met dic Teologiese Skool het ook na Potchefstroom verhuis aan die begin van 1905 die Literariese Departement, waaruit die inrigting vir Christelike hoër onderwys in 1919 ontstaan het. 
In 1911 het dr. Du Toit prof. J.Lion Cachet opgevolg as professor aan dic Teologiese Skool en daaraan verbind gebly tot 1939 - 'n lang tyd van arbeid aan die Christelike hoër onderwys!

Die stryd om die literariese hoër onderwys het eintlik begin met dic totstandkoming van die Unie in 1910. Dit het al gou vir die Kuratore van die Teologiese Skool duidelik geword dat 'n opdraande stryd voorlê vir die behou en ontwikkeling van die Literariesc Departement. Die stryd het begin omdat sinds 1910 die gedagte al meer en meer vaste vorm aangeneem het dat die hcle universitêre lewe in Suid-Afrika hervorm moet word. Die ou Kaapse Universiteit, wat net eksaminerende werk verrig het, kon nie langer aan die groeiende akademiese behoeftes van die jong land voldoen nie. Daar moes ook doserende universiteite kom. En hulle koms sou die Literariese Departement ingrypend beïnvloed. Aan hierdie saak het dr. Du Toit 'n beslissende aandeel geneem.

Op die Kerkraad van Potchefstroom is voortdurend aanhangig gemaak die stigting van 'n Gereformeerde Normaalskool. Op 22 Desember 1911 het die Kerkraad egter besluit om geld in te samel vir dic benoeming van ' $n$ professor in die Pedagogiek aan die Teologiese Skool.

Dr. Du Toit het hieraan sy volle steun toegesê. Op die Algemene Vergadering van Transvaal is in Januarie 1913 besluit om 'n kommissie te benoem - dr. Du Toit was lid daarvan - om die Algemene Sinode te adviseer in verband met die opleiding van Christelike onderwysers. Die Algemene Sinode van Maart 1913 het die saak noukeurig oorweeg maar kon tot geen bepaalde besluit kom nie. Die Transvaalse Algemene Vergadering het op sy vergadering in Februarie 1914 tog besluit dat 'n klas vir onderwyscrs begin moes word, dat erkenning vir die Normaalklasse by die Owerheid aangevra word en dat geld vir die doel ingesamel word. Maar van die klasse het niks tereg gekom nie. Dr. Du Toit het egter die ideaal bly koester: in 1920 kon die P.U.K. vir K.H.O. daarmee begin! Maar die behoud van die Literariese 
Departement was selfs aktucler.

Die Kuratorium van die Teologiese Skool, waarop dr. Du T'oit adviserend gesit het, het reeds in hul rapport aan dic Sinode van 1913 die wenslikheid aanbeveel om aansoek by die Regering te doen vir subsidie aan die Literariese Departement maar alleen op so 'n weg waarop dit deur die Kuratore aanvaar kon word. Dit is ernstig oorweeg op grond van ,de te stichten Staatsuniversiteit". Die Kuratore is toe opgedra om die saak by dic Regering aanhangig te maak - en daarby het dr. Du Toit 'n belangrike rol gespeel. In 1916 het dic saak van die Literariese Departement werklik akuut geword, toc die nuwe Wetgewing op die Hoër Onderwys aangeneem is. Dit het toe geword 'n saak van affiliasie, inkorporasie of net subsidie, of...

Die nuwe Universiteite het in April 1918 in werking getree en daarmee was die Literariese Departement vereensaam. Die Sinode van 1918 het toe voor hom gehad 'n uiters belangrike rapport van 'n Subkommissie (W. Postma, F. Postma en J.D. du Toit). Dr. Du Toit het hier saam met prof. F. Postma die deurslaggewende rol gespeel: amalgamasie met Bloemfontein, affiliasie met Pretoria, inkorporasie by Die Universiteit van Suid-Afrika of ' $n$ Vrye Universiteit was die keuseweë. Die Sinode kon geen vrymoedigheid tot inlywing by enige van die ander inrigtings vind nie. Sy beswaar het gegeld die sogenaamde Gewetensklousule. Dit het besluit tot ernstiger aansoek om subsidie. Dr. Du Toit, 'n goeie vriend van die destydse Minister van Onderwys, F.S. Malan, het in die stilte baie gedoen en verrig gekry. 'n Subsidie is eindelik verkry op voorwaarde dat die Literariese Departement afgeskei word. Dit het geskied op 1 April 1919. Maar dit was maar net 'n tydelike reeling. Die P.U.K. vir K.H.O. moes inkorporeer of ophou om te werk! Op die Spesiale Sinode van 1920 het die woord van dr. Du Toit die finale deurslag gegee tot inkorporasie. By die indiening van die Private Wetsontwerp het Jacob Daniël du Toit as deputaat van die Gereformecrde Kerk opgetrce as die kragtige getuie, naas Ferdinand Postma en Willem Jacobus de Klerk. 
So het veral deur die persoonlike invloed van dr. Du Toit die P.U.K. sy Private Wet No. 25 van 1921 verkry - maar sonder sy volle naam en onder die Gewetensklousule van die Onderwyswet van 1916 .

Dr. Du Toit sou nog verder meehelp aan die verkryging van die volle naam en aan die stryd teen die Gewetensklousule.

Hy het ook deeltydse lid van die personeel van die P.U.K. geword - eers as spesiale lektor en vanaf 1929 as professor in Hebreeus en Ou-Testamentiese Eksegese.

Dr. Du Toit het ook 'n leidende aandeel geneem aan die stig. ting en ontwikkeling van die Vereniging vir Kristelik-Nasionaal Hoër Onderwys (en sy opvolgers). Hierdie Vereniging is gestig in 1917. Sy hoofdoel was, volgens sy Konsep-statute (Die Kerkblad, 15 Junir 1917) om 'n inrigting vir K.N.H.O. te stig en in stand te hou. Dr. Du Toit was lid van die Hoofbestuur van die Vereniging. Na die afskeiding van die P.U.K. vir K.H.O. het die Vereniging homself opnuut gekonstitueer as die V.K.H.O. met 'n drieledige doel: verwydering van die Gewetensklousule in die Wet, geldelik steun aan die P.U.K. vir K.H.O., verspreiding van literatuur en ander propagandamiddels. Dr. Du Toit was weer eens lid van die Hoofbestuur. In 1925 is die Vereniging verander in Die Christelike Unie met hoofdoel: bestudering, propagering en toepassing van die Christelike beginsels volgens die Calvinistiese lewens- en wêreldbeskouing. Dr. Du Toit was raadsman en medewerker veral van die Kommissie vir Publisiteit. Een van die belangrikste werksaamhede van die organisasies was dic stryd teen die Gewetensklousule. In 1927 het die Kristelike Unie 'n brosjure uitgegee oor Die Gewetensklousule vir ons Universiteite en die Groepbeginsel, waarin ook die hand van dr. Du Toit gesien kan word.

Dr. Du Toit het intussen ook sy gedagtes oor dic Christelike Wetenskap in artikels geformuleer. Van besondere belang in die 
verband is sy waardevolle bydrae oor Methode van Echte Studie. Hy tree dus op as akademikus en as pedagoog van die Christelike hoër onderwys.

Ek wil die uiteensetting afsluit deur 'n voorlopige poging tot sistematisering van sy opvoedkundige denke.

Hy het geen sisteem ontwikkel nie - daarvoor was hy teoloog en nie pedagoog nie. Maar sy reeks artikels oor C.N.O. en oor die Christelike Wetenskap en sy brosjures oor Christelijke Onderwys met of zonder Dogma en oor De Methode van echte Studie wys tog selfs by 'n vlugge studie op sekere belangrike beginsels en grondgedagtes. Maar manne wat met hom saamgewerk het, weet ook van die groot gewig van sy gedagtes by die saamstelling van enige verslag - kerklik of opvoedkundig. Baie van die verslae is byna ' $n$ woordelikse vertolking van sy denke.

Dr. Du Toit was wel geen geskoolde opvoedkundige nie. Hy het homself egter goed op hoogte gestel met die grondbeginsels van die opvoeding.

Op sy siening oor onderwyssake het sonder twyfel die volgende invloed uitgeoefen: sy huislike en skoolopvoeding, die bestudering van sy vader se geskrifte (De Christelijke School, de Vrije School) en sy handelinge as Superintendent van Opvoeding in Transvaal, kennismaking met Paedagogische Beginselen van Herman Bavinck, Wat is het doel van C.N.S. onderwijs? van Jan Woltjer en Geschiedenis van het Christelijk Lager Onderwijs van J. Kuiper. (Vgl. Aanteekeningen op sy brosjurc Christelijke Onderwijs met of zonder Dogma) en die tradisionele beskouing van die Gereformeerde Kerk van Suid-A frika.

Die vraagstukke waarmee hy hom veral besig gehou het, is: die gees en rigting van die onderwys, godsdiensonderwys, skoolbeheer, die opleiding van onderwysers.

Uit sy vader se geskrifte het hy geleer: (a) Die onderwys en 42 
opvoeding van die jeug rus op die skouers van die ouers. (b) Die Kerk moet toesig hou dat die skole Christelik is en dat die ouers die doopbelofte nakom. (c) Die Owerheid moet die pogings van die ouers en Kerk geldelik ondersteun. In die Transvaal het ds. S.J. du Toit 'n stelsel van Staatsondersteunde Skole ingevoer en ontwikkel, wat die ideaal van sy seun gebly het; die vrye skool met staatsteun, later die Groepskool.

Sy deelname aan die Sinodale Vergaderinge van sy Kerk het hom reeds vanaf die sitting in Maart 1904 die volgende tradisie leer ken: Die Sinode (1882) voel die behoefte aan skole heeltemal deur die Kerk ingerig en onder goeie kerklike opsig met behartiging van die vereiste kundighede. Daarom beveel dit aan dat kerkrade en gemeentes kerklike skole oprig. Dit is van oordeel dat die ouers self die onderwys vir hul kinders moet besorg en bekostig. As die Regering besluit om die onderwys te help bevorder en aan elke skool, waarin voldoende onderwys in die nodige burgerlike wetenskappe gegee word, ' $n$ toelae toe te ken na 'n redelike maatstaf, dan mag 'n Christelike skool die toelaag met eweveel reg ontvang as elke ander skool, behoudens onafhanklike vryheid in die godsdiensonderwys. En die Sinode (1904) waarsku ten emstigste teen die teenswoordige rigting van die goewermentsonderwys en beveel aan die stigting van vrye skole waarin ons godsdiens, taal en geskiedenis in waarde gehou word, en dit wek ouers, onderwysers en kerkrade om hierin saam te werk.

Wat die gees en rigting van sy ideale skool betref, het hy dit, saam met die ander Bestuurslede, gestel toe in Potchefstroom De Voorbereidende School as 'n vrye Christelike skool gestig, in stand gehou en beheer is. So lui die formulering: (a) Dit is die beliggaming van ons beginsels op die geheel van die onderwys: (1) Alle onderwys moet gegee word in die Christelike sin tot eer van die Naam van die Here. (2) Alle onderwys moet nasionaal wees en die moedertaal die medium. (3) Die reg van die ouers in die opvoeding van hul kinders moet gehandhaaf word en (4) Godsdiensonderwys moet elke dag gegee word: 
Bybelse Geskiedenis, gebed, Psalm; selfs die geskiedenis van die eie kerk en cie dogmatiese onderwys.

Wat die godsdiensonderwys betref, het ons op twee geleenthede 'n duidelike formulering van sy beskouings: in 1908 in sy Christelijke Onderwijs met of zonder Dogma en in 1939 in sy toespraak op die C.N.O.-kongres. Dit is die opsomming van sy ideaal: (1) Onder ,godsdiensonderwys" in die Christelike Skool verstaan ek in hoofsaak die onderrig in die Bybelse Geskiedenis en die Christelike Leer. (2) Hierdie onderwys moet nie hermeties van die ander skoolwerksaamhede afgesluit word nie maar moet daarmee een organiese geheel vorm. (3) Die onderrig in die Bybelse Geskiedenis moet nie bloot 'n mededeling van feite wees nie maar moet geskraag word deur die geloofsoortuiging van die ouers van die skoolgaande kinders soos dit vasgelê is in die Belydenisskrifte wat die ouers aanvaar het. (4) Die onderrig in die Christelike Leer, wat rekening moct hou met die ontwikkelingspeil van die kinders, moet nie kleurloos wees nie maar moet ooreenkomstig dic belydenis van die ouers van skoolgaande kinders gegce word. (5) Ten opsigte van ons $\lambda$ frikanervolk sou dit beteken dat die onderrig in die Bybelse Geskicdenis en in die Christelike Leer konform dic Belydenisskrifte van die drie Hollandse kerke in Suid-Afrika moet geskied. (6) Hicrdic doel kan alleen bercik word deur 'n stelscl van vryce, Christclike, A frikaansc, nasionale skolc. Dr. Du Toit was ten aansicn van punt 4 'n geborc pedagogiese tcoloog. Hy het vir dic gebruik van die katki. sasies van sy Kerk 'n verwerking van dic Heidelbergse Kategismus opgestel wat aan die goeic eise van dic Opvoedkunde voldoen. Hierdic bockic was bedoel vir dic oucr kinders. Ek het 'n soortgelyke boekie vir dic jonger kinders verwerk na dic voorbeeld van 'n bockic deur ds. J.H. Kruger. By die verwerking van die bockic vir dic kleintjics het ck die fynsinnige leiding van dr. Du Toit deurgaans gehad. Sy opmerking aan my getuig van diepsinnigc insig: „Dic mocilikste dogmatick denkbatar is die samestelling ran 'n Katcgismusbockic vir klein kinders". klke woord en sin in dalardic boekic het hy rakgesien. Elkeen wat met hom siamge. 
werk het, weet hoe minitieus presies hy kon wees!

Die sesde punt in sy beskouing oor die godsdiensonderwys lei sy beskouings oor die skoolstelsel in. Hy wou 'n vrye, Christelike, Afrikaans-nasionale skool hê. Hy het sy gedagtes oor die skoolstelsel op baie plekke gestel maar nergens duideliker as in sy referaat voor die groot Kongres in 1917: Die Plek van die Skool in ons Samelewing. In die stryd om die skool is daar drie magte: die Staat, die Kerk en die ouers. Die kinders hoort nie aan die Staat nie, en daarom die Skool ook nie. Die suiwer posisie van die Staat is: dit moet hierdie volksbelang (die skool) dien met die publieke geld en dit moet kontroleer of die onderwys tegnies voldoende is. Die kinders hoort in strenge sin ook nie aan die Kerk nie, en daarom ook nie die Skool nie. Die Kerk bou nie regstreeks skole nie maar dit eis van die ouers, wat lidmate daarvan is, dat hulle hul kinders na Christelike skole stuur, omdat hulle gedoopte kinders en dus lidmate van die Kerk is. Die Kerk moet die Christelike onderwys op morele wyse steun, waar nodig. Die kinders hoort aan die Ouers, en daarom ook die Skool. Maar omdat die Skool 'n instelling in die maatskaplike lewe is en dit 'n gesamentlike onderneming van 'n hele aantal ouers is, hoort die Skool eintlik aan die gesamentlike ouers soos hulle groepsgewys openbaar word. Gesamentlik staan hier teenoor individueel. Die Skool is nie 'n huisskool nie maar 'n selfstandige instelling wat die maatskappy dien sodat die kind vir sy plek in die maatskappy klaargemaak word. So kom die ouer tot sy reg: hy bepaal in samewerking met sy mede-ouer die karakter en rigting van die Skool. Teenoor Staat, Kerk en Maatskappy is die Skool verantwoording verskuldig, maar daarin bly dit selfstandig. Niemand mag die Skool in sy reg krenk nie, solank dit van sy standpunt en optrede behoorlik rekenskap gee. Die Staat moet alle skole gelykheid voor die Wet gee en uit die publieke beurs op 'n regmatige grondslag steun.

Op die Kongres van 1918 is toe besluit op 'n stelsel van Groepskole. Dr. Du Toit moes met twee ander predikante (di. S.W. van 
Niekerk, N.H. of G. Kerk, en L.E. Brandt, N.H. Kerk) die besluite van die Kongres saamvat in 'n memorandum wat hulle drie namens die Afrikaanse Kerke voor die Malherbe-kommissie moes lê en verdedig. Malherbe deel in sy Verslag (1920) in Art. 125 mee dat die volgende punte die idee van Groepskole stel:

„(1) Groepen van gelijkgezonde ouders, die dezelfde taal, godsdiens, geschiedenis en tradities hebben, moeten het recht hebben door hun eigen schoolkommissies afzonderlike scholen op te richten en te besturen, waar zij onderwijzers moeten kunnen benoemen met dezelfde taal, godsdienst en tradities als zij zelf; en zulke onderwijzers moeten gekozen worden uit een lijst van behoorlik gekwalifiseerde onderwijzers, die van tijd tot tijd door het Departement moet worden uitgegeven;

(2) dat zulke groepen de bevoegdheid zullen hebben het onderwijs in taal, godsdienst en geschiedenis in deze scholen te regelen, en de geest en richting van de school te bepalen;

(3) dat gekombineerde groepen het recht zullen hebben hun eigen Normaal Kolleges op te richten voor het opleiden van onderwijzers, en dat de onderwijzers die in zulke kolleges opgeleid zijn, dezelfde rechten en voorrechten zullen hebben, als onderwijzers met dezelfde kwalifikaties, die elders opgeleid zijn;

(4) dat wanneer kinderen in deze afzonderlike scholen gcinspekteerd worden, zij op zulk een wijze zullen becordeeld worden, dat or ten volle rekening zal gehouden worden met de zicnswijze van de groep, met betrekking tot taal, godsdienst en geschiedenis;

(5)dat, of uit een voorgeschreven aantal van zulke schoolkom. missies, of uit de schoolkommissies van een zekere kring een raad gekozen zal worden, die de algemene belangen van de verschillende scholen zal behartigen; terwijl het Goewernement op die Raad zal worden vertegenwoordigd door personen aangesteld door het Goevernement uit de groepen van ouders van dezelfde taal, godsdienst en traditie;

(6) dat scholen, opgericht in overeenstemming met dic voor- 
gaande voorstellen, voor zover de standaard van onderwijs betreft, onderworpen zullen zijn aan de wetten en regulaties, die van tijd tot tijd in de Provincie van kracht mogen wezen;

(7) dat scholen, die op deze wijze opgericht worden, op dezelfde voet zullen geplaatst worden als gewone Goevernementscholen, wat betreft gebouwen, salarissen van het personeel, uitrusting, beurzen, transport, enz."

Dr. Du Toit het hom ten slotte baie bekommerd gemaak oor die opleiding van onderwysers. Hy was van oortuiging dat geen onderwysstelsel, selfs nie of juis nie die Groepstelsel nie, tot bevrediging van die ouergemeenskap kan funksioneer sonder die regte onderwyser nie. Die onderwyser staan tog in loco parentis.

Wat van die karakter en gees van die onderwys, soos deur die ouergemeenskap verlang, teregkom, hang af van die onderwyser. En na die mening van dr. Du Toit kon die regte onderwysers verkry word alleen deur aan jongmense die regte opleiding te gee. Daarom het hy reeds as predikant van Potchefstroom gepleit vir die benoeming van 'n pedagoog aan die Teologiese Skool of vir die oprigting van 'n Christelike Normaalskool op Potchefstroom. Hy was dan ook, naas prof. F. Postma, die sterkste bepleiter van die invoering van 'n onderwysersopleidingskursus aan die P.U.K. vir K.H.O.. In 1920 is dit verwesenlik toe begin is met die opleiding van studente vir die Unie-O-1.-sertifikaat-eksamen. En daarom het hy onder al sy baie werksaamhede in 1923 aan die ondergetekende by sy studie vir die nuwe M.Ed.-eksamen leiding gegee in die vak S.Afr. Onderwysgeskiedenis. As 'n persoonlike getuienis mag ek hier net meedeel dat prof. Du Toit, net so kragtig as prof. Postma, my aangemoedig het om vanaf $1920 \mathrm{my}$ op die Opvoedkunde toe te lê. Die benoeming van die eerste voltydse professor in die Opvoedkunde aan die P.U.K. het een van sy lewensideale sien verwesenlik: die opleiding van onderwysers aan 'n inrigting vir Christelike hoër onderwys. 
Ten slotte moet ek uit opvoedkundige oogpunt die rustige lesing van die brosjure De Methode van Echte Studie sterk aanbeveel. Dit is 'n opvoedkundige metode vir die hoër onderwys.

J. Chr. Coetzee. 